\title{
A case of imported Leishmania infantum cutaneous leishmaniasis; an unusual presentation occurring 19 years after travel
}

\author{
Amy Crowe ${ }^{1 *}$, John Slavin ${ }^{2}$, Damien Stark ${ }^{3}$ and Craig Aboltins ${ }^{1,4}$
}

\begin{abstract}
Background: Leishmania infantum is a flagellated protozoan parasite that is able to parasitize blood and tissue. Leishmania species cause a spectrum of clinical disease with cutaneous, visceral or mucosal involvement. L. infantum is recognised as a cause of visceral leishmaniasis $(\mathrm{VL})$ and is less commonly reported as a cause of cutaneous leishmaniasis $(C L)$ from countries around the Mediterranean basin. This is the first report of imported L. infantum CL to Australia and is remarkable for a 19 year period between the patient's exposure to an endemic region, and the manifestation of symptoms.

Case presentation: A 76 year old Italian-born man presented to our institution with a non-healing lesion over his upper lip, abutting his nasal mucosa. The patient had travelled to Italy, an endemic area for L. infantum 19 years earlier but had resided in Australia, a non-endemic area since. Histopathology performed on a biopsy of the lesion demonstrated findings consistent with $\mathrm{CL}$. A species specific polymerase chain reaction (PCR) performed on the tissue detected $L$. infantum. The patient had complete clinical recovery following treatment with Liposomal amphotericin B at a dose of $3 \mathrm{mg} / \mathrm{kg}$ for five days followed by a subsequent $3 \mathrm{mg} / \mathrm{kg}$ dose at day ten.
\end{abstract}

Conclusions: $L$. infantum should be recognised as a cause of imported $C L$ in returned travellers from the Mediterranean. In this case, the incubation period for $L$. infantum $C L$ was at least 19 years. This case adds to the described spectrum of clinical presentations of leishmaniasis and supports the theory of parasite persistence underlying natural immunity and recurrence of disease. Clinicians should consider $L$. infantum $C L$ in the differential diagnosis of a non-healing skin lesion in any patient who reports travel to the Mediterranean, even when travel occurred several years before clinical presentation.

Keywords: Cutaneous leishmaniasis, Parasitology, Neglected tropical infectious diseases, Microbiology, Liposomal amphotericin

\section{Background}

Leishmania species are flagellated protozoa that parasitize the blood or tissue. Infection is transmitted to humans by the bite of a female Phlebotomus sand fly. The classical form of visceral disease, "kala-azar", is characterized by fever, anaemia and splenomegaly. Leishmaniasis is recognized by the world health organization (WHO) as a neglected tropical disease [1]. It causes significant morbidity and mortality worldwide with an estimated 12 million people infected in over 88 countries [1]. L. infantum is

\footnotetext{
* Correspondence: amy.crowe@svha.org.au

'Department of Infectious Diseases, St Vincent's Hospital, Melbourne, Australia

Full list of author information is available at the end of the article
}

well recognized as the etiological agent of VL in southern Europe, the Middle East and North Africa [2]. CL due to $L$. infantum has only more recently been recognized. Del Giudice et al, described L. infantum as a cause of CL in 3 patients and 3 adults from southern France in 1998 [3]. More recently cases from Portugal and Malta have been described $[4,5]$. Herein we describe the first case of imported L. infantum CL into Australia. This case is made even more remarkable by the 19 year period between our patient traveling to an endemic region and presenting with disease. The implication this has for our understanding of the disease pathogenesis and immunity are discussed.

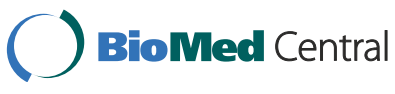

(c) 2014 Crowe et al.; licensee BioMed Central Ltd. This is an Open Access article distributed under the terms of the Creative Commons Attribution License (http://creativecommons.org/licenses/by/2.0), which permits unrestricted use, distribution, and reproduction in any medium, provided the original work is properly credited. The Creative Commons Public Domain Dedication waiver (http://creativecommons.org/publicdomain/zero/1.0/) applies to the data made available in this article, unless otherwise stated. 


\section{Case presentation}

A 76 year-old man was referred to our hospital with a 10 month history of an enlarging plaque on the cutaneous aspect of the upper lip. He had presented six months previously with symptoms of nasal stuffiness and epistaxis. The lesion began as a small nodule.

Past medical history included type-2 diabetes mellitus, ischaemic heart disease and hypertension. The man was born in Italy. In 1952 he immigrated to Australia. He resided in the Northern Territory for seven years then had resided in the outer suburbs of Melbourne, Victoria, since. 19 years prior to presentation he had travelled back to Italy and southern France. He denied any other travel. The man could not recall any similar facial lesions in the past.

Examination revealed a $2 \times 1.7 \mathrm{~cm}$ plaque involving the cutaneous aspect of the upper lip bordering the nostrils (Figure 1a). The lesion had a moderate exudate and some scaling. The patient was afebrile with no splenomegaly.

Two $2 \mathrm{~mm} \times 4 \mathrm{~mm}$ biopsies of the lesion were taken. Histopathology (Figure 2) revealed mixed suppurative and granulomatous inflammation in the dermis with prominent plasma cells. Innumerable dot-shaped microorganisms of approximately 3 microns in diameter were seen filling histiocytes. Giemsa stain of these microorganisms was positive, morphologically consistent with amastigotes of Leishmania species. Periodic acid Schiff and Grocott (silver) stains for fungi were negative.

The identification and speciation of $L$. infantum was confirmed by two molecular methods. Polymerase chain reaction (PCR) targeting of the internal transcribed spacer (ITS) region and subsequent digestion of the amplicon with the restriction enzyme HaelII was performed as previously described [6]. The restriction fragment length polymorphism (RFLP) banding pattern was consistent with $L$. donovani complex. In order to confirm genotyping results and to further speciate, the sample was analyzed by another PCR-RFLP genotyping method targeting the miniexon gene according to the genotyping scheme described elsewhere [7]. The banding pattern was consistent with $L$. infantum.
Standard bacterial cultures revealed no growth at 48 hours. A human immunodeficiency virus (HIV) antibody test was negative. Baseline renal function was within normal range. A peripheral lymphocyte count demonstrated a slight decrease in CD4 T- cells $(0.48 \times$ $10^{9} / \mathrm{L}$ ), this persisted post treatment and no cause for this was identified.

Due to the anticipated pain of intra-lesional injections, infection with a species that causes visceral disease and concern regarding mucosal involvement, the patient was given intravenous liposomal amphotericin B $(3 \mathrm{mg} / \mathrm{kg})$ daily for five days with a further infusion at day ten. Review a month later showed minor improvement in the size of the lesion with persistent cracking and erythema. Suspecting secondary bacterial infection a course of antibiotics (Cephalexin) was prescribed. A second biopsy was performed three months post treatment. This revealed marked granulomatous and inflammatory reactions with occasional amastigotes. A further dose of liposomal amphotericin B at $3 \mathrm{mg} / \mathrm{kg}$ was given. Topical hydrocortisone was prescribed to manage surrounding inflammation. On review eight months after treatment, there was complete resolution of the lesion (Figure $1 \mathrm{~b}$ ).

\section{Conclusions}

Leishmaniasis is distinguished by both clinical presentation and geographic origin. VL is predominantly caused by $L$. donovani complex, consisting of $L$. donovani and $L$. infantum [2]. CL is predominantly caused by $L$. major, L. tropica, L. donovani and L. aethiopica in the old world (Middle East, Pakistan, Africa) and by L. mexicana, $L$. amazonensis and L. braziliensis in the new world (Central and South America, Amazon basin) [2].

Post kala-azar dermal leishmaniasis, diffuse cutaneous leishmaniasis and leishmania recividans are included in the clinical spectrum of leishmaniasis [2]. Post kala-azar dermal leishmaniasis follows VL and is most commonly caused by $L$. donovani [2]. Diffuse cutaneous leishmaniasis is more commonly described in new world CL. Leishmaniasis recividans is an uncommon presentation of $\mathrm{CL}$, almost exclusively caused by L. tropica [8-10] and characterized by

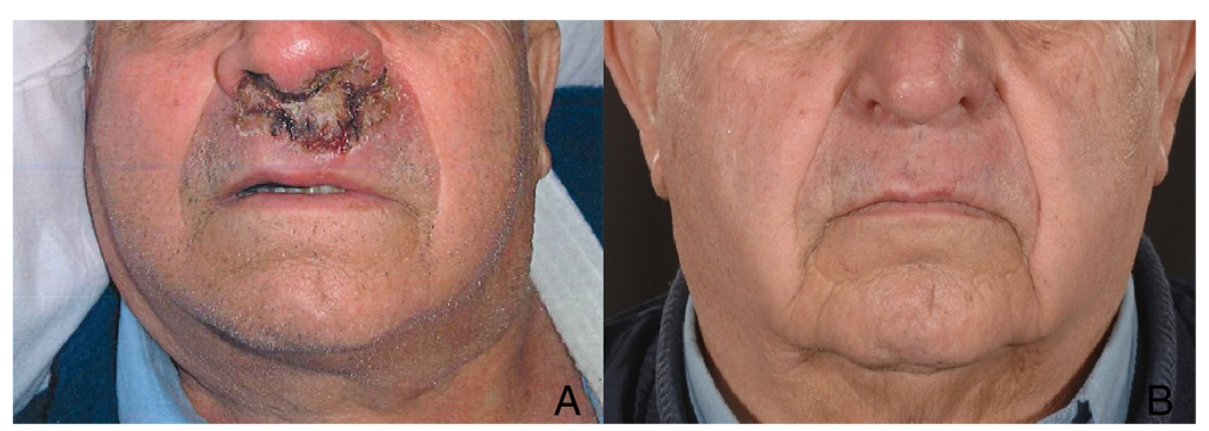

Figure 1 Upper lip lesion (A) Appearance of lesion prior to treatment (B) Resolution of lesion 8 months post treatment. 


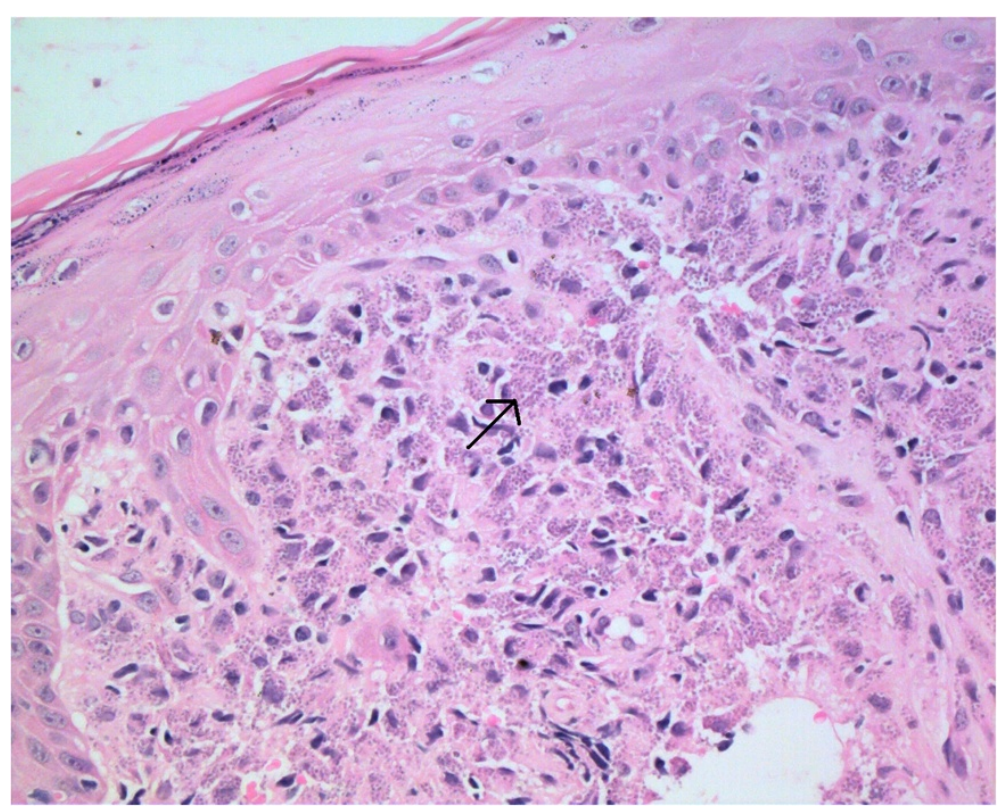

Figure 2 Upper lip punch biopsy. H\&E stain (x40 magnification) demonstrating innumerable dot-shaped microorganisms suggestive of amastigote of Leishmania species.

a relapsing course and a paucity of amastigotes on histopathological examination of skin lesions [10]. Periods of up to 43 years between episodes of leishmaniasis recividans have been described [8].

L. infantum VL in the Mediterranean is a well described zoonosis with various Phlebotomus species of sand-fly acting as the vector and dogs serving as the primary reservoir $[11,12]$. L. infantum causing limited cutaneous leishmaniasis (LCL) has been described in adults and children from southern France, Italy, Portugal and Malta [3-5]. L. infantum LCL mainly occurs in exposed areas and usually has a nodular appearance, although infiltrative lesions have also described [3-5].

Our patient did not present with symptoms until 19 years after travel to an endemic country. Previously reported cases of CL imported into Australia report onset of symptoms within months of travel to, or residence in an endemic country [13-15].

This case report describes a very uncommon case of L. infantum LCL with a very long incubation period. Reactivation of parasites in this case is likely to have occurred in the setting of declining immune function, caused by advancing age and CD4 lymphopenia. Prolonged incubation periods with old world CL have previously been described [16] and and low CD4 cell subsets have been recognized as a risk factor for recurrence in HIV-1 and L. infantum co-infection [17,18]. Asymptomatic $L$. infantum parasitaemia has been documented in HIV-1 co-infected patients in endemic areas [19]. It is less likely this case represents a case of Leishmania recividans, as our patient has several inconsistent features; no history of preceding episodes, abundant amastigotes present on the histopathology and infection with a Leishmania species that has never been described to cause leishmania recividans.

A recent review of 213 cases in returned travelers identified 20 cases of old-world CL caused by $L$. donovani complex, which encompasses L. infantum [20]. 71\% were tourists from the Mediterranean. In a series of cases imported into Australia, two were identified (by PCR) to be caused by $L$. infantum. One case presented as VL, the other presented with post-kala-azar dermal leishmaniasis. Both patients had a history of travel to Greece [21].

More recent and therefore local acquisition in our patient is unlikely. No locally acquired case of leishmaniasis in humans has ever been reported in Australia. A novel species of leishmaniasis causing CL has been described in Australian macropods (Kangaroos and Wallaroos) [22] but this species is phylogenetically distinct from $L$. infantum (the species identified by PCR in our case). Phlebotomus species of sandflies have been identified from various Australian regions (mainly Queensland) [23], so vector transmission via an imported reservoir (e.g.- infected imported dogs) is a theoretical possibility, however our patient did not report any contact with imported dogs.

Diagnosing CL in non-endemic areas is difficult and often delayed. Tissue histopathology is crucial for diagnosis. On hematoxylin and eosin stain, amastigote stages (intracellular form) can be seen within macrophages in the dermal layer. The cytoplasm of the amastogotes stains light blue, whilst the nucleus and kinetoplast (bar-shaped 
mitochondrial structure) stain red with Giemsa stain. Amastigotes within tissue specimens can be differentiated from fungal organisms because they do not stain positive with periodic acid-Schiff, mucicarmine, or silver stain [24].

Leishmania promastigotes (extracellular form) may be demonstrated from culture. Selective media such as Novy, MacNeal and Nicolle's medium are required for growth. Promastigote stages can be seen on a wet mount from media growth and stain with Giemsa [24].

Leishmaniasis serology and antigen based skin tests are problematic in non-endemic areas and are not available in Australia. Leishmaniasis PCR on tissue is sensitive and specific and allows species differentiation $[6,7,21]$.

Evidence on the best management of CL caused by $L$.infantum is lacking [25]. Successful treatment with both pentavalent antimony and amphotericin has been described. We used liposomal amphotericin B with good results due to the concern about mucosal involvement and infection with a species more commonly implicated in VL.

In summary we present an unusual case of $L$. infantum CL in a 76 year old Italian man with mild CD4 lymphopenia and a history of travel to an endemic area 19 years preceding presentation. This case demonstrates that CL caused by $L$. infantum may have a long incubation period. L. infantum should be recognized as a cause of imported $\mathrm{CL}$ in patients who have travelled to the Mediterranean.

\section{Consent}

Written informed consent was obtained from the patient for publication of this case report and any accompanying images. A copy of the written consent is available for review by the Editor of this journal.

\section{Abbreviations}

CM: Centimetre; CL: Cutaneous leishmaniasis; LCL: Limited cutaneous leishmaniasis; HIV: Human immunodeficiency virus; KG: Kilogram; PCR: Polymerase chain reaction; RFLP: Restriction fragment length polymorphism; VL: Visceral leishmaniasis.

\section{Competing interests}

The authors declare that they have no competing interests.

\section{Authors' contributions}

A/ProfessorCA conceived the paper, contributed content to the manuscript and critically reviewed the manuscript. Dr AC performed a literature review and drafted the manuscript. A/Professor JS provided the histopathology images and reviewed the manuscript for important intellectual content. Dr DS performed the molecular diagnostics and contributed information regarding this to the manuscript. All authors read and approved the final manuscript.

\section{Authors' information}

Dr Amy Crowe is an Infectious Diseases Physician and advance trainee in Medical Microbiology currently working at Peter MacCallum Cancer Hospital, East Melbourne and St Vincent's Hospital Melbourne, Australia. A/Professor John Slavin is an anatomical pathologist working at St Vincent's Pathology, Melbourne, Australia. Dr Damien Stark, PhD is a senior molecular scientist working at the Department of Microbiology, SydPath, St Vincent's Hospital, Darlinghurst, Australia. A/ProfCraig Aboltins is an Infectious Diseases Physician at St Vincent's Hospital Melbourne and The Northern Hospital, Epping, Australia.

\section{Acknowledgements}

We would like to acknowledge Dr Harsha Sheorey, St Vincent's Pathology, Melbourne for his assistance in preparing this manuscript.

\section{Author details}

'Department of Infectious Diseases, St Vincent's Hospital, Melbourne, Australia. ${ }^{2}$ Department of Pathology, St Vincent's Hospital, Melbourne, Australia. ${ }^{3}$ Department of Microbiology, SydPath, St Vincent's Hospital, Darlinghurst, New South Wales, Australia. ${ }^{4}$ Department of Infectious Diseases, Northwest Academic Centre, The University of Melbourne, Epping, Victoria, Australia.

Received: 26 December 2013 Accepted: 29 October 2014

Published online: 27 November 2014

\section{References}

1. Anonymous: WHO. http://www.who.int/leishmaniasis/en/. Website accessed December 2013.

2. Pearson RD, Sousa AQ: Clinical spectrum of leishmaniasis. Clin Infect Dis 1996, 22:1-13.

3. del Giudice P, Marty P, Lacour JP, Perrin C, Pratlong F, Haas H, Dellamonica P, Le Fichoux Y: Cutaneous Leishmaniasis Due to Leishmania infantum. Case reports and literature review. Arch Dermatol 1998, 134(2):193-198.

4. Campino L, Pratlong F, Abranches P, Rioux JA, Santos-Gomes G, Alves-Pires C, Cortes S, Ramada J, Cristovão JM, Afonso MO, Dedet JP: Leishmaniasis in Portugal: enzyme polymorphism of Leishmania infantum based on the identification of 213 strains. Trop Med Int Health 2006, 11(11):1708-1714.

5. Pace D, Williams TN, Grochowska A, Betts A, Attard-Montalto S, Boffa MJ, Vella C: Manifestations of paediatric Leishmania infantum infections in Malta. Travel Med Infect Dis 2011, 9(1):37-46.

6. SchÖnian G, Nasereddin A, Dinse N, Schweynoch C, Schallig HD, Presber W, Jaffe CL: PCR diagnosis and characterization of Leishmania in local and imported clinical samples. Diagn Microbiol Infect Dis 2003, 47(1):349-358.

7. Marfurt J, Nasereddin A, Niederwieser I, Jaffe CL, Beck HP, Felger I: Identification and differentiation of Leishmania species in clinical samples by PCR amplification of the miniexon sequence and subsequent restriction fragment length polymorphism analysis. J Clin Microbiol 2003, 41(7):3147-3153.

8. Marovich M, Lira R, Shepard M, Fuchs GH, Kruetzer R, Nutman TB, Neva FA Leishmaniasis recidivans recurrence after 43 years: a clinical and immunologic report after successful treatment. Clin Infect Dis 2001, 33(7):1076-1079.

9. Masood S, Naveed S, Alvi RU: Infiltrated leishmaniasis recidivans cutis on the face: a rare clinical presentation. Trop Doct 2012, 42(2):120-121.

10. Sharifif I, Fekri A, Aflatoonian MR, Khamesipour A, Mahboudi F, Dowlati Y, Nadim A, Modabber F: Leishmaniasis recidivans among school children in Bam, South-East Iran, 1994-2006. Int J Dermatol 2010, 49(5):557-561.

11. Baldelli R, Piva S, Salvatore D, Parigi M, Melloni O, Tamba M, Bellini R, Poglayen G: Canine leishmaniasis surveillance in a northern Italy kennel. Vet Parasitol 2011, 179(1-3):57-61.

12. Lachaud L, Dedet JP, Marty P, Faraut F, Buffet P, Gangneux JP, Ravel C, Bastien $\mathrm{P}$, Bustien P: Working party for the notification of human leishmanioses in France. Surveillance of leishmaniases in France, 1999 to 2012. Euro Surveill 2013, 18(29):20534.

13. Storer $E$, Wayte J: Cutaneous leishmaniasis in Afghani refugees. Australas J Dermatol 2005, 46(2):80-83.

14. Maguire G, Bastian I, Arianayagam S, Bryceson A, Currie BJ: New world cutaneous leishmaniasis imported into Australia. Pathology 1998, 30(1):73-76.

15. Konecny P, Stark DJ: An Australian case of new world cutaneous leishmaniasis. Med J Aust 2007, 186(6):315-317.

16. Weiss F, Vogenthaler N, Franco-Paredes C, Parker SR: Leishmania tropica- induced cutaneous and presumptive concomitant viscerotropic leishmaniasis with prolonged incubation. Arch Dermatol 2009, 145(9):1023-1026.

17. Aebischer T: Recurrent cutaneous leishmaniasis: a role for persistent parasites? Parasitol Today 1994, 10(1):25-28.

18. Bourgeois N, Lachaud L, Reynes J, Rouanet I, Mahamat A, Bastien P: Long-term monitoring of visceral leishmaniasis in patients with AIDS: relapse risk factors, value of polymerase chain reaction, and potential impact on secondary prophylaxis. J Acquir Immune Defi Syndr 2008, 48(1):13-19. 
19. Colomba C, Saporito L, Vitale F, Reale S, Vitale G, Casuccio A, Tolomeo M Maranto D, Rubino R, Di Carlo P, Titone L: Cryptic Leishmania infantum infection in Italian HIV infected patients. BMD Infect Dis 2009, 9:199.

20. Wall E, Watson J, Armstrong M, Chiodini PL, Lockwood DN: Epidemiology of imported cutaneous Leishmaniasis at the Hospital for tropical disease, London, United Kingdon: use of polymerase chain reaction to identify the species. Am J Trop Med Hyg 2012, 86(1):115-118.

21. Stark $D$, van Hal $S$, Lee $R$, Marriott $D$, Harkness J: Leishmaniasis an emerging imported infection: report of 20 cases from Australia. J Travel Med 2008, 15(5):351-354

22. Rose K, Curtis J, Baldwin T, Mathis A, Kumar B, Sakthianandeswaren A, Spurck T, Low Choy J, Handman E: Cutaneous leishmaniasis in red kangaroos: isolation and characterization of the causative organisms. Int J Parasito 2004, 34(6):655-664.

23. Dyce A, Wellings G: Phlebotomine Sandflies (Diptera: Psychodidae) from caves in Australia. Parasitologia 1991, 33:193-198.

24. Versalovic J, Carroll KC, Funke G, Jorgensen J, Landry ML, Warnock DW: Manual of Clinical Microbiology. 10th edition. Washington DC: ASM Press; 2011. Print.

25. González U, Pinart M, Reveiz L, Alvar J: Interventions for Old World cutaneous leishmaniasis. Cochrane Database of Syst Rev 2008, (4). Art. No.: CD005067. doi:10.1002/14651858.CD005067.pub3.

doi:10.1186/s12879-014-0597-x

Cite this article as: Crowe et al:: A case of imported Leishmania infantum cutaneous leishmaniasis; an unusual presentation occurring 19 years after travel. BMC Infectious Diseases 2014 14:597.

\section{Submit your next manuscript to BioMed Central and take full advantage of:}

- Convenient online submission

- Thorough peer review

- No space constraints or color figure charges

- Immediate publication on acceptance

- Inclusion in PubMed, CAS, Scopus and Google Scholar

- Research which is freely available for redistribution 